\title{
Author Correction: Genetic dissection of clonal lineage relationships with hydroxytamoxifen liposomes
}

\author{
Ryan C. Ransom 1,2, Deshka S. Foster 1,2, Ankit Salhotra1,2, Ruth Ellen Jones (1) 1,2, Clement D. Marshall ${ }^{1,2}$, \\ Tripp Leavitt (10 1, Matthew P. Murphy ${ }^{1,2}$, Alessandra L. Moore1, Charles P. Blackshear ${ }^{1}$, Elizabeth A. Brett', \\ Derrick C. Wan ${ }^{1} \&$ Michael T. Longaker ${ }^{1,2}$
}

Correction to: Nature Communications https://doi.org/10.1038/s41467-018-05436-6, published online 30 July 2018

In the original version of this article, the authors inadvertently omitted Elizabeth A. Brett, who contributed to the generation of the histology figures, from the author list. This has now been corrected in both the PDF and HTML versions of the Article.

Published online: 19 October 2018

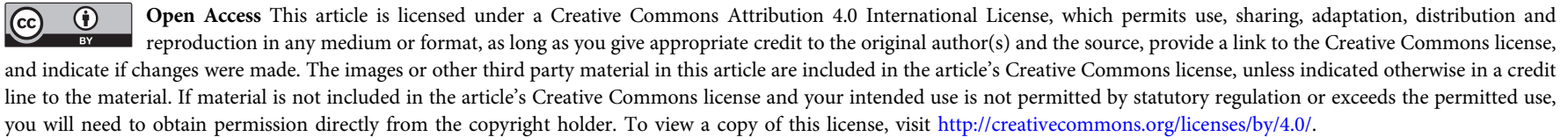

(C) The Author(s) 2018

\footnotetext{
${ }^{1}$ Department of Surgery, Division of Plastic and Reconstructive Surgery, Stanford University School of Medicine, Stanford 94305 CA, USA. ${ }^{2}$ Institute for Stem Cell Biology and Regenerative Medicine, Stanford University School of Medicine, Stanford 94305 CA, USA. Correspondence and requests for materials should be addressed to M.T.L. (email: longaker@stanford.edu)
} 